\title{
The effect of doubling the minimum wage on employment: evidence from Russia
}

\author{
Alexander Muravyev ${ }^{1,2^{*}}$ and Aleksey Oshchepkov ${ }^{3}$
}

\footnotetext{
* Correspondence: amuravyev@hse.ru ${ }^{1}$ Saint Petersburg Branch, National Research University Higher School of Economics, Kantemirovskaya street 3 bld. 1, Saint Petersburg 194100, Russia

2IZA, Bonn, Germany

Full list of author information is available at the end of the article
}

\begin{abstract}
We take advantage of a natural experiment in the minimum wage setting in Russia to study the employment consequences of large hikes in the minimum wage. In September 2007, the Russian government raised the federal minimum wage from 1100 to 2300 Rubles and simultaneously gave the regions the power to set their own minima above the federal threshold. In studying the effect of this reform, we follow the approach proposed by David Card and compare changes in employment rates and other labor market outcomes before and after the hike across regions with different shares of affected workers. We find some evidence of adverse effects of the 2007 hike in the minimum wage on employment. They are mostly visible in lower employment rates among the youth, as well as the increased informalization of employment.
\end{abstract}

JEL codes: J38, J23

Keywords: Minimum wages, Unemployment, Informal employment, Russia

\section{Introduction}

The minimum wage is one of the most controversial issues in labor economics, economic policy, and politics. A typical purpose of minimum wage policies is to support low-wage workers and thereby fight inequality and poverty (Belser and Rani 2015). Less frequently, minimum wage policies are advocated as a means to correct imperfections in the labor market, regarding employers' monopsony power in particular (e.g., Boal and Ransom 1997). However, the effectiveness of the minimum wage in achieving these goals is highly contested. From the theoretical viewpoint, the standard labor supply and demand model suggests that the minimum wage may increase unemployment, especially among low-skilled workers (Stigler 1946). There are also concerns that the minimum wage promotes informalization of the labor market, which is particularly relevant in the developing world. Moreover, the benefits of the minimum wage in monopsonistic environments have been questioned in a number of recent contributions, such as Danziger (2010).

The empirical evidence regarding the employment effects of the minimum wage remains contradictory and inconclusive. For example, the seminal symposium published in the Industrial and Labor Relations Review (ILLR) in 1992 provided highly conflicting results regarding this issue. The estimated effect of the minimum wage on the employment of less-skilled workers ranged from negative (Neumark and Wascher 1992) and

(c) 2016 Muravyev and Oshchepkov. Open Access This article is distributed under the terms of the Creative Commons Attribution 4.0 International License (http://creativecommons.org/licenses/by/4.0/), which permits unrestricted use, distribution, and reproduction in any medium, provided you give appropriate credit to the original author(s) and the source, provide a link to the Creative Commons license, and indicate if changes were made. 
zero (Card 1992) to positive (Katz and Krueger 1992). This controversy continues to date. For example, Dube et al. (2010) find no disemployment effects in restaurants and other low-wage sectors in the USA, Dolton et al. (2012) report no or a small positive impact of the minimum wage on employment in the UK, while Sen et al. (2011) find significant disemployment effects among teens in Canada. As the most comprehensive survey of the literature up to 2006, the review study by Neumark and Wascher (2008) concludes that the minimum wage has a negative effect on the employment opportunities of less-skilled workers and no effect on overall employment. However, Belman and Wolfson (2014, p. 15) point out that the estimated effects of the minimum wage "are either statistically nonsignificant or are too small in magnitude to be economically meaningful".

Most empirical papers in this field commonly focus on relatively small increases in the nominal minimum wage, typically below $20 \%$. For instance, in the USA, the magnitude of the federal minimum wage hikes examined in empirical studies-including those published in the 1992 special issue of ILLR—did not exceed $30 \%$. Similarly, each of the regular increases in the UK minimum wage between 1999 and 2007 did not exceed $15 \%$ (Dolton et al. 2012). It is plausible that the absence of robust evidence regarding the employment effects of the minimum wage stems from this particular feature of the empirical literature. Indeed, from the theoretical viewpoint, employers' adjustment costs may deter them from laying off low-wage workers in response to a small increase in the minimum wage. From the estimation perspective, small variation in the minimum wage can complicate econometric identification, especially when minimum wage hikes are regular and expected or when there are measurement errors in the data.

In this paper, we present new evidence on the employment effects of a large increase in the minimum wage. We take advantage of a natural experiment that occurred in Russia in September 2007 when a comprehensive reform of the minimum wage setting was introduced. Firstly, the federal minimum wage was sharply raised from 1100 to 2300 Rubles. ${ }^{1}$ Secondly, the minimum wage setting was decentralized with regions receiving the right to set their own regional minima above the federal floor. Some regions made use of this opportunity instantaneously, whereby the minimum wage in these regions increased by much more than the $109 \%$ implied by the federal law. With over 80 regions being characterized by very diverse economic conditions-including employment and wages-and abrupt changes in its economic policy, Russia provides a very good laboratory for studying the economic consequences of the minimum wage.

To estimate the impact of the 2007 increase in the minimum wage on employment, we rely on the methodological approach proposed by Card (1992). It is based on comparing labor market outcomes before and after the minimum wage change across regions with different fractions of affected workers (namely, workers earning between the old and new minimum wages). This approach has found many applications in the empirical literature, both in the USA (e.g., Card and Krueger 1995; Wessels 2007) and internationally (e.g., Bazen and Skourias 1997 for France and Stewart 2002 for the UK).

The main strength of this paper is the use-for identification purposes-of the unique data with extremely large variation in the minimum wage as well as labor market outcomes across 85 regions of Russia. Our study is among the first to exploit this quasiexperimental setting - and the 2007 reform in particular-in analyzing the labor market 
effects of the minimum wage. ${ }^{2}$ Another strength of the paper is its focus on a broad range of labor market outcomes, including not only employment and unemployment rates among various sub-groups in the population but also informal employment. We argue that data from post-transitional Russia-a country that combines essential features of developed and developing economies-are particularly well suited for studying the effect of the minimum wage on such multiple outcomes.

The main results of the paper can be summarized as follows. We find some evidence of adverse effects of the minimum wage on employment. Specifically, the 2007 minimum wage hike was associated with a decrease in youth employment and increased informality. The result is largely driven by regions that introduced their own minimum wages above the federal floor. We attribute the latter to the larger magnitude of the minimum wage hikes in these regions compared to those that simply adopted the federal minimum wage. Another possibility is that the regional increases in the minimum wage were less anticipated than the federal one, whereby it was impossible for employers to adjust to them in advance. Importantly, the results are in line with the findings in Muravyev and Oshchepkov (2013), which adopts the region panel data approach (e.g., Neumark and Wascher 1992) to studying the effect of the minimum wage on employment in Russia.

The remainder of the paper is organized as follows. Section 2 provides the institutional background of the minimum wage setting in Russia. Section 3 outlines the methodology of our empirical analysis. Section 4 describes the data, before Section 5 presents and discusses the empirical results. Finally, Section 6 concludes.

\section{Institutional background}

This section offers only a brief summary of the institutional background regarding the minimum wage setting in Russia, given that the details can be found in previous studies, particularly Muravyev and Oshchepkov (2013) and Lukiyanova and Vishnevskaya (2015). The minimum wage in Russia already existed during the central planning era, in the form of the lowest monthly wage in the wage grid. However, the term minimum wage was not used at that time. It only appeared in national law after the start of the country's transition to a market economy. ${ }^{3}$ Since the early 1990s, the minimum wage has been defined as the minimum pay per month of full-time employment (typically $40 \mathrm{~h}$ per week). Until 2007, the minimum wage was determined at the federal level. The federal minimum applied to all groups of workers without any differences by age, occupation, or industry. It was set at the same level across regions, with the exception of those in the North and Far East, where the so-called Northern wage multipliers applied. ${ }^{4}$

In the mid-1980s, the ratio of the minimum to average wage (the Kaitz ratio) amounted to about $35-40 \%$, which is a typical level for OECD countries. In the 1990s-a period of economic reforms accompanied by hyperinflation-there was a dramatic erosion of the real minimum wage in Russia, despite regular minimum wage hikes. As a result, by the start of the new century, the minimum wage amounted to a mere $6 \%$ of the average wage. A number of more substantial increases were introduced between 2001 and 2007, although given the double-digit inflation in the country, they only helped to keep the Kaitz ratio at about 10 \% (Muravyev and Oshchepkov 2013). 
This changed in September 2007, when a comprehensive reform of the minimum wage was introduced. First, the nominal minimum wage was raised by $109 \%$. Second, the minimum wage setting was decentralized. Since September 2007, Russia's regions have the right to define their own regional minima (which may be sector-specific) above the federal threshold. Third, the 2007 reform of the minimum wage setting eliminated the link between the minimum wage and the Northern multiplier, previously set in federal law.

As a result of the reform, the nominal minimum wage more than doubled and the Kaitz ratio exceeded $20 \%$ nationwide. The "fraction affected"-namely the share of workers with wages above the old minimum wage but below the new minimum wage-approached $6 \%$. Moreover, as many regions opted for own regional minima above the federal threshold, considerable variation in the nominal minimum wage across the regions emerged. Importantly, due to the very diverse levels of wages across the country's regions, the cross-regional variation in terms of the Kaitz ratio was even more dramatic. For example, Muravyev and Oshchepkov (2013) report the Kaitz index range between 8 and $46 \%$ in September 2007. Similarly, the fraction affected varied from almost zero in rich regions to double-digit numbers in less developed ones. In sum, the reform generated considerable variation in the nominal minimum wage as well as in the Kaitz index and the fraction affected.

\section{Methodology}

In order to estimate the impact of the 2007 hike in the minimum wage on employment, we rely on the methodological approach first proposed by David Card (1992). In his study, Card analyzed the impact on teenage employment of the 1990 increase in the minimum wage in the USA, from $\$ 3.35$ to $\$ 3.80$. The general idea behind his approach may be summarized as follows: "A rise in the federal minimum wage will typically affect a larger fraction of workers in some states than in others. This variation provides a simple natural experiment for measuring the effect of legislated wage floors, with a "treatment effect" that varies across states depending on the fraction of workers initially earning less than the new minimum" (Card 1992, p. 22). Formally, the approach leads to estimating the following equation in the cross section of regions or states:

$$
\Delta \text { Employment }_{i}=\alpha+\beta * \text { Fraction_affected }_{i}+\gamma * \text { Controls }_{i}+\varepsilon_{i}
$$

where $\Delta$ Employment $_{i}$ is the difference in average employment rates before and after the hike in the minimum wage in region $i$; Fraction_affected ${ }_{i}$ is the proportion of workers who earn wages between the old and new minimum wages; Controls $s_{i}$ is a list of control variables; and $\varepsilon_{i}$ is a conventional error term. A negative and statistically significant coefficient on variable Fraction_affected ${ }_{i}$ would imply disemployment effects of the minimum wage. ${ }^{5}$

Equation (1) is the baseline econometric model in our analysis. We estimate it by OLS allowing for heteroscedastic standard errors (using the Huber/White/sandwich estimator of variance). In addition, we consider several extensions of Eq. (1) and estimate the model using various sub-samples of the data.

First, we attempt to control for the heterogeneity across the regions, which has become a primary focus in the empirical literature (e.g., Allegretto et al. 2013). With this purpose, we include controls measuring the trend in the dependent variables before the 
reform (as in Card 1992), the change in industrial production over 1 year preceding the reform, and the share of rural population in the regions.

Second, we distinguish between the federal and regional minimum wage hikes (see Wessels 2007; Bazen and Le Gallo 2009). In particular, we conduct analyses separately for the regions that simply adopted the new federal threshold for the minimum wage (regions with the federal minimum) and those that opted for higher wage floors (regions with own minima). We argue that these two groups differ not only in the magnitude of the minimum wage hikes (the regional minima are by definition larger, and often much larger, than the federal minimum) but also in employers' ability to anticipate (and hence, adjust in advance to) the new wage floors. In particular, while the federal hikes were regular and more-or-less expected by employers throughout the 2000s, the institution of the regional minimum wages was first introduced in the federal law $\mathrm{N}$ 54-FZ passed on April 20, 2007. Regional hikes in the minimum wage adopted between April 2007 and the fall of 2007 are likely to have been much more unexpected among employers than any of the federal hikes in the 2000s.

Third, we exclude regions where the Northern wage multipliers applied. This robustness check is motivated by the fact that these regions have a particular structure of the economy, with high shares of extracting industries, high wages, and low unemployment. More importantly, the increase in the federal minimum wage in 2007 was accompanied by eliminating the Northern wage multipliers (which were used to inflate the old federal minimum), whereby the fraction affected in these regions is rather low and contributes little to econometric identification.

Next, we check whether our key results are sensitive to introducing weights that capture different sizes of Russian regions in terms of population. The use of such weights has been a common robustness check in many prior studies of the minimum wage at the level of regions or industries (see Krueger 1995; Bazen and Skourias 1997; Baker et al. 1999 as well as Wessels 2007). In our case, the main motivation comes from the fact that Russia has a number of small regions with a very peculiar economic structure (e.g., economies centered on a particular industry), which often become outliers in empirical analyses. In addition, the use of weights helps to estimate the effect of the minimum wage on the economy at large. ${ }^{6}$

We also re-estimate the regressions using the dependent variable measured not as a difference in employment rates but rather as a difference in their logs, similarly to Wessels (2007). Finally, following Stewart (2002), we run a placebo test in which we use the dependent variable lagged by 1 year (change in employment between November 2006 and November 2005) and the fraction affected by the 2007 reform.

\section{Data}

The data for this study come from several sources. The first source is the Labor Force Survey (LFS) administered by the Russian Statistical Agency (Rosstat). The survey is a repeated cross section conducted on a quarterly basis (in February, May, August, and November). The data contain information on employment in each of Russia's regions, including various demographic groups (in particular, the youth, women, and loweducated workers). ${ }^{7}$ The LFS covers all regions of Russia and contains several hundred thousand observations. Importantly, the survey is representative at the regional level. From the viewpoint of this paper, one of the main strengths of the Russian LFS is the 
ability to differentiate between formal and informal employment. ${ }^{8}$ One of its main weaknesses is the absence of wage data, given that respondents are not asked questions on wages to minimize survey non-response.

With these data at hand, we are able to compute the following dependent variables measuring labor market outcomes in Russian regions on a quarterly basis:

- Employment rate (EMPLOY), defined as the number of employed people aged 15 to 72 divided by the total population aged 15 to 72 .

- Formal employment rate (FORMAL), defined as the number of people (aged 15 to 72) employed in the formal sector divided by the total population aged 15 to 72 .

- Informal employment rate (INFORM), defined as the ratio of the number of people (aged 15 to 72) employed in the informal sector to the total population, for people aged 15 to 72 .

- Unemployment rate (UNEMPL), defined as the number of unemployed divided by the economically active population, for people aged 15 to 72 . As is standard in labor market statistics, the economically active population comprises employed and unemployed people.

- Youth employment rate (YOUT_E), same as the general employment rate but computed for people aged 15 to 24.

- Youth unemployment rate (YOUT_U), same as the general unemployment rate but computed for those aged 15 to 24 .

- Female employment rate (FEM_E), defined as the number of employed women aged 15 to 72 divided by the total number of women aged 15 to 72 .

- Female unemployment (FEM_U), defined as the number of unemployed women aged 25 to 72 divided by the number of economically active women in the same age bracket.

- Employment rate among low-educated workers (LOW_E), defined as the number of employed people who have basic or general secondary education among the total population aged 15 to $72 .^{9}$

- Unemployment rate among low-educated workers (LOW_U), defined as the number of unemployed people who have basic or general secondary education among the economically active population with basic or general secondary education, for the age bracket 15 to 72 .

We supplement these data with information on regional minimum wages obtained from databases of national and regional laws, such as Consultant Plus, ${ }^{10}$ as well as web sites of regional governments and other internet sources.

Next, we add data on the distribution of monthly wages across the Russian regions prior to the 2007 minimum wage reform. These data are collected by Rosstat from a detailed survey of employers conducted on an annual basis in April (henceforth, the April survey of employers). To date, this is the only survey that provides detailed wage data, particularly regarding the percentage of workers whose wages lie within a specific bracket, for all regions of the country. We use the data from the 2007 wave of the survey, as the closest to the minimum wage hike in September 2007. With this information at hand, we are able to compute the key independent variable in our regression analysis, fraction affected. Note that due to the small number of brackets, we have to resort to linear interpolation. ${ }^{11}$ 
The main strength of the April survey of employers is its large scale (over 90,000 organizations in all major industries and of all ownership types) and nationwide coverage. However, there are also two important limitations: the survey excludes small businesses yet includes wages of part-time workers. The former implies an underestimation of the fraction affected (small firms-which are omitted from the survey-typically pay lower wages compared to large firms) while the latter leads to an overestimation of the fraction affected (a worker may have a monthly wage below the new minimum wage due to engaging in part-time employment). We assess the importance of these limitations for our estimation results using additional control variables that capture at the regional level (a) the share of workers employed in small businesses in 2006 and (b) the share of part-time workers in 2006. These additional data are taken from Rosstat.

Finally, we supplement all these data with information on the dynamics of output (change in industrial production) and shares of urban vs. rural population, which are also taken from the official publications by Rosstat.

The descriptive statistics of the data are shown in Table 1. The average fraction affected amounts to almost $6.46 \%$ for the federal increase in the minimum wage. Once the regional hikes are taken into account, the respective number rises to $8.15 \%$. The huge variation across the regions in the fraction affected is notable, ranging from 0.05 to $20.16 \%$ for the federal hike and from 0.05 to $28.06 \%$ for the regional ones. The data also show considerable variation in labor market outcomes across regions; for example,

Table 1 Descriptive statistics of key variables

\begin{tabular}{|c|c|c|c|c|c|}
\hline Variable & Mean & Median & Min & Max & SD \\
\hline Fraction affected (federal) & 6.46 & 6.25 & 0.05 & 20.16 & 4.37 \\
\hline Fraction affected & 8.15 & 7.59 & 0.05 & 28.06 & 5.59 \\
\hline Kaitz index (federal) & 21.60 & 22.08 & 6.13 & 45.44 & 7.14 \\
\hline Kaitz index & 24.18 & 24.26 & 6.13 & 47.45 & 8.44 \\
\hline EMPLOY & 62.27 & 62.68 & 29.64 & 76.79 & 6.38 \\
\hline FORMAL & 51.51 & 52.64 & 22.16 & 72.64 & 9.01 \\
\hline INFORM & 10.69 & 10.68 & 2.03 & 22.77 & 4.31 \\
\hline UNEMPL & 7.06 & 6.17 & 0.79 & 32.33 & 4.45 \\
\hline YOUT_E & 34.51 & 34.96 & 13.83 & 48.80 & 6.62 \\
\hline YOUT_U & 14.82 & 13.11 & 3.47 & 61.22 & 8.97 \\
\hline FEM_E & 58.59 & 58.24 & 21.05 & 75.61 & 6.82 \\
\hline FEM_U & 6.63 & 5.72 & 0.70 & 38.29 & 4.66 \\
\hline LOW_E & 42.79 & 42.70 & 21.56 & 62.77 & 6.37 \\
\hline LOW_U & 10.94 & 9.48 & 2.52 & 31.44 & 6.02 \\
\hline Ind. production index & 109.95 & 109.35 & 72.60 & 159.00 & 15.62 \\
\hline Share of rural population & 32.38 & 31.40 & 0.00 & 100.00 & 15.73 \\
\hline Share of workers in small firms & 7.32 & 6.81 & 0.66 & 26.41 & 3.97 \\
\hline Share of part-time workers & 5.78 & 4.76 & 0.15 & 31.06 & 4.37 \\
\hline Population, thousands & 1631.00 & 1171.50 & 18.00 & 10443.00 & 1610.94 \\
\hline
\end{tabular}

Notes: All variables except population are measured in percentages. Fraction affected is the percentage of workers who earn wages between the old and new minimum wages, based on the distribution of wages in April 2007. Kaitz index is the ratio of the minimum wage and the average wage in the region, measured in November 2007. Ind. production index is the index of industrial production between the third quarter of 2006 and the third quarter of 2007. Share of workers in small firms is computed as the share of workers employed by small businesses divided by the working-age population; the data are from 2006. Labor market outcomes (variables EMPLOY-LOW_U) are measured in November 2007 
the employment rate varies from 30 to $77 \%$ (the average is $62 \%$ ) and the unemployment rate varies from 1 to $32 \%$ (the average is $7 \%$ ).

As the constructed variable fraction affected has not been used in prior research on the minimum wage in Russia, it may require additional validation. One way of doing so is to compare it with another common measure of the significance of the minimum wage, the Kaitz index. In contrast to the fraction affected variable, the Kaitz index has been used in several papers on Russia, including Kobzar (2009) and Muravyev and Oshchepkov (2013). ${ }^{12}$ Figures 1 and 2 plot fraction affected and Kaitz index against each other. Figure 1 represents the case of the federal minimum, while Fig. 2 also accounts for the regional minima. The two measures-fraction affected and Kaitz index-prove to be closely related regardless of whether we consider the federal or regional level. The correlation coefficients exceed $90 \%$, thus suggesting that the fraction affected variable indeed captures regional variation that is useful in identifying the effect of the 2007 minimum wage hike.

It may be of interest to compare the pre-reform characteristics of the regions that introduced their own regional minima with those that did not do so by the fourth quarter of 2007. The results are shown in Table 2. In the regions that did not introduce own minimum wages, the fraction affected is equal to $7.03 \%$. The regions that opted for higher regional minimum wages saw a considerably higher fraction affected, at an average level of $12.63 \%$. Had they opted for the federal minimum wage instead, the fraction affected was a mere $4.18 \%$. Thus, the regional hikes provide an important source of variation in the data.

There are also sizable differences in labor market outcomes across the two groups of regions. For example, the employment rate is $3.11 \%$ higher in the regions that opted for own minimum wages. Similarly, the unemployment rate is $3.02 \%$ lower in these regions compared with those that followed the federal minimum wage. The data suggest that own minima were introduced by the regions that performed on average better than the others. ${ }^{13}$ However, many of the differences across the two groups of regions are statistically insignificant despite possibly being economically large. This hints at the considerable heterogeneity among the regions within each group.

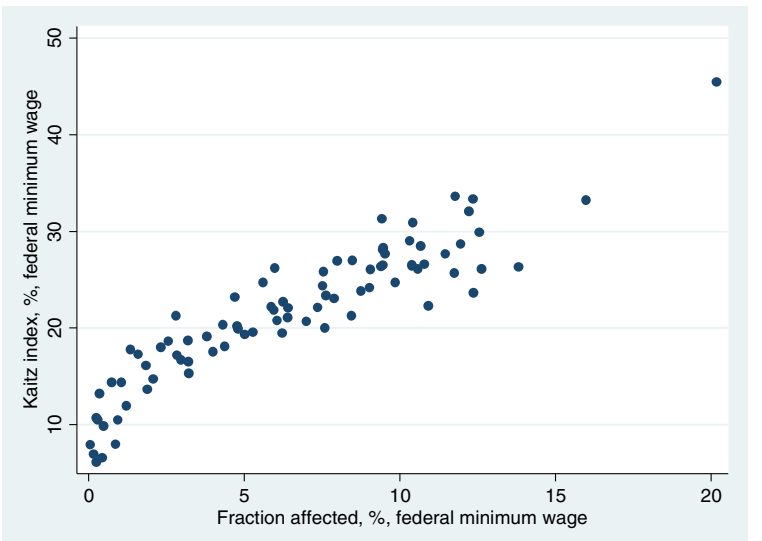

Fig. 1 Fraction affected and Kaitz index plotted against each other, the federal minimum wage 


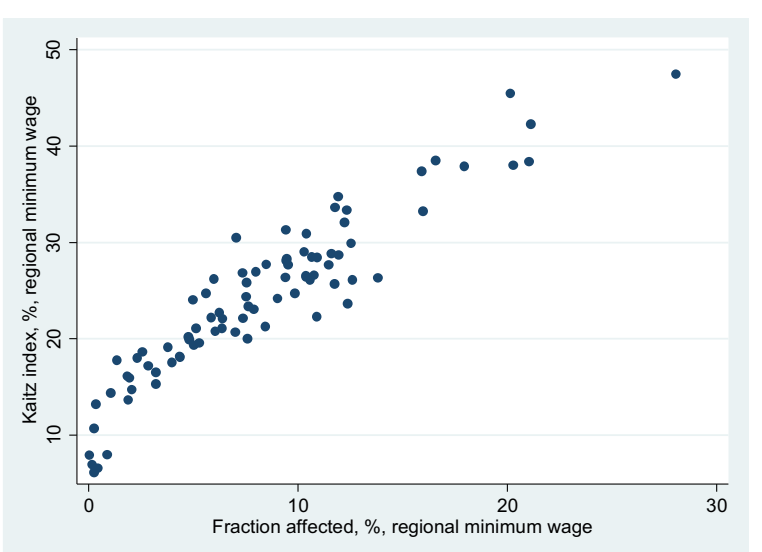

Fig. 2 Fraction affected and Kaitz index plotted against each other, accounting for the regional minimum wage

While interesting and informative, the above comparison between the two groups of regions does not eliminate concerns about the potential endogeneity of the regional minimum wages, which may lead to biased estimates. Lukiyanova and Vishnevskaya (2015) provide some evidence against the endogeneity concern, suggesting that economic considerations were not the main driving force behind the regional governments' decisions to introduce regional minimum wages. However, this evidence is by no means conclusive. Given our lack of reliable data to address the endogeneity issue in a rigorous way, we leave it for further research.

\section{Results and discussion}

The main results of our empirical analysis are shown in Tables 3, 4, and 5. The tables provide estimation results for the ten dependent variables chosen, namely employment rate EMPLOY, formal employment rate FORMAL, informal employment rate INFORM, general unemployment rate UNEMPL, youth employment rate YOUT_E, youth unemployment rate YOUT_U, female employment rate FEM_E, female unemployment rate FEM_U, employment rate among low-educated workers LOW_E, and unemployment rate among low-educated workers LOW_U. Table 3 contains the results for the most parsimonious specification without any control variables. Table 4 shows the regressions in which the only control variable is a lagged dependent variable (capturing the trend in the dependent variable between November 2005 and November 2006). Table 5 provides estimates for the regressions with additional controls, namely the change in industrial production 1 year before the reform of the minimum wage as well as the share of rural population. The results in Tables 3, 4, and 5 are arranged in the following way: we start with the regressions for all the regions (panel A) then repeat the analysis for the regions that simply adopted the federal minimum wage (panel B), before focusing on the regions that introduced their own minima above the federal floor (panel C). Subsequently, we drop the Northern regions from the sample (panel D) and finally repeat the regressions for all the regions using their population as weights (panel E). To save space, the tables only report the key coefficient of interest-on the fraction affected variable. 
Table 2 Comparison of the pre-reform characteristics across the two groups of regions

\begin{tabular}{lllll}
\hline Variable & $\begin{array}{l}\text { Regions with federal } \\
\text { minimum wage, N=68 }\end{array}$ & $\begin{array}{l}\text { Regions with own } \\
\text { minimum wage, N=17 }\end{array}$ & Difference & $p$ value \\
\hline Fraction affected & 7.03 & 12.63 & -5.60 & 0.00 \\
Kaitz index & 13.28 & 11.96 & 1.33 & 0.18 \\
EMPLOY & 60.46 & 63.56 & -3.11 & 0.10 \\
FORMAL & 49.77 & 53.36 & -3.58 & 0.15 \\
INFORM & 10.67 & 10.21 & 0.47 & 0.66 \\
UNEMPL & 8.48 & 5.46 & 3.02 & 0.07 \\
YOUT_E & 32.16 & 33.33 & -1.17 & 0.55 \\
YOUT_U & 16.97 & 12.63 & 4.34 & 0.08 \\
FEM_E & 56.86 & 59.78 & -2.92 & 0.13 \\
FEM_U & 8.11 & 4.95 & 3.16 & 0.08 \\
LOW_E & 41.97 & 44.37 & -2.41 & 0.14 \\
LOW_U & 12.56 & 8.65 & 3.91 & 0.07 \\
Ind. production index & 108.12 & 108.34 & -0.22 & 0.96 \\
Share of rural population & 34.46 & 24.10 & 10.36 & 0.01 \\
Share of workers in small firms & 6.66 & 9.95 & 3.29 & 0.00 \\
Share of part-time workers & 6.09 & 4.91 & 1.18 & 0.33 \\
Population, thousands & 1522.74 & 2340.71 & -817.97 & 0.06 \\
\hline
\end{tabular}

Notes: Fraction affected is based on regional minimum wages and wage data from April 2007. Labor market outcomes (variables EMPLOY-LOW_U) as well as Kaitz index are measured in November 2006. Ind. production index is the index of industrial production between the third quarter of 2005 and the third quarter of 2006 . The other variables are measured as of 2006

We start with the results in Table 3. The regressions in panel A show statistically insignificant results for all the regions. While most coefficients have signs consistent with the presence of adverse effects of the minimum wage and some even have $t$-statistics greater than one (in the regressions with informal employment rate and female employment rate as the dependent variable), none are statistically significant at the conventional levels. The test for the difference in the key coefficient in columns 2 and 3-which is reported beneath the main estimation results in panel A-suggests no differential effects of the minimum wage on formal and informal employment $(p$ value $=0.22$ )

The results of estimating the model using the sub-sample of the regions that simply followed the federal minimum wage (panel B) also show statistically insignificant results, with all $t$-statistics being substantially smaller than one. As in the above case, there is no statistically significant difference in the coefficients on the fraction affected variable in the regressions with formal and informal employment ( $p$ value $=0.89)$.

By contrast, panel C shows several statistically significant coefficients estimated on the sub-sample of the regions that raised the minimum wage above the federal floor. In particular, the results suggest that the minimum wage hike reduced the formal employment rate and increased informal employment, as well as reduced the youth employment rate and increased youth unemployment. The test for the same effect of the minimum wage hike on formal and informal employment is rejected at the $5 \%$ level ( $p$ value $=0.011)$. Since the coefficient on the overall employment rate is statistically insignificant, there is apparently a move of workers from the formal sector to the 
Table 3 Regression results for the most parsimonious specification without control variables

\begin{tabular}{|c|c|c|c|c|c|c|c|c|c|c|}
\hline & (1) & $(2)$ & (3) & (4) & (5) & (6) & (7) & (8) & (9) & (10) \\
\hline & EMPLOY & FORMAL & INFORM & UNEMPL & YOUT_E & YOUT_U & FEM_E & FEM_U & LOW_E & LOW_U \\
\hline \multicolumn{11}{|c|}{ Panel A: all regions, $N=85$} \\
\hline \multirow{2}{*}{$\begin{array}{l}\text { Fraction } \\
\text { affected }\end{array}$} & 0.000 & -0.050 & 0.049 & -0.010 & -0.088 & 0.069 & -0.062 & -0.003 & 0.025 & -0.021 \\
\hline & $(0.052)$ & $(0.057)$ & $(0.038)$ & $(0.043)$ & $(0.100)$ & $(0.113)$ & $(0.052)$ & $(0.046)$ & $(0.089)$ & $(0.070)$ \\
\hline$R^{2}$ & 0.000 & 0.005 & 0.015 & 0.000 & 0.012 & 0.004 & 0.010 & 0.000 & 0.001 & 0.000 \\
\hline \multicolumn{11}{|c|}{ H0: fraction affected[FORMAL] $=$ fraction affected [INFORM], $p$ value $=0.224$} \\
\hline \multicolumn{11}{|c|}{ Panel B: regions with federal minimum wage, $N=68$} \\
\hline \multirow{2}{*}{$\begin{array}{l}\text { Fraction } \\
\text { affected }\end{array}$} & 0.057 & 0.015 & 0.037 & -0.076 & 0.006 & -0.133 & -0.029 & -0.058 & 0.003 & -0.083 \\
\hline & $(0.089)$ & $(0.107)$ & $(0.070)$ & $(0.088)$ & $(0.147)$ & $(0.184)$ & $(0.096)$ & $(0.094)$ & $(0.145)$ & $(0.146)$ \\
\hline$R^{2}$ & 0.006 & 0.000 & 0.005 & 0.010 & 0.000 & 0.008 & 0.001 & 0.005 & 0.000 & 0.004 \\
\hline \multicolumn{11}{|c|}{ H0: fraction affected[FORMAL] $=$ fraction affected [INFORM], $p$ value $=0.887$} \\
\hline \multicolumn{11}{|c|}{ Panel C: regions with own minimum wage, $N=17$} \\
\hline \multirow{2}{*}{$\begin{array}{l}\text { Fraction } \\
\text { affected }\end{array}$} & -0.097 & $-0.203^{* *}$ & $0.106^{*}$ & 0.003 & $-0.291^{*}$ & $0.295^{* *}$ & -0.121 & -0.027 & -0.043 & 0.007 \\
\hline & $(0.075)$ & $(0.088)$ & $(0.054)$ & (0.029) & $(0.153)$ & $(0.133)$ & $(0.072)$ & $(0.045)$ & $(0.125)$ & $(0.065)$ \\
\hline$R^{2}$ & 0.122 & 0.215 & 0.115 & 0.001 & 0.212 & 0.209 & 0.155 & 0.021 & 0.008 & 0.000 \\
\hline \multicolumn{11}{|c|}{ H0: fraction affected[FORMAL] $=$ fraction affected[INFORM], $p$ value $=0.011$} \\
\hline \multicolumn{11}{|c|}{ Panel D: Northern regions are dropped, $N=60$} \\
\hline \multirow{2}{*}{$\begin{array}{l}\text { Fraction } \\
\text { affected }\end{array}$} & 0.022 & -0.005 & 0.024 & 0.031 & $-0.161^{*}$ & $0.181^{*}$ & 0.004 & 0.029 & 0.030 & 0.050 \\
\hline & $(0.049)$ & $(0.057)$ & $(0.041)$ & $(0.040)$ & $(0.090)$ & $(0.094)$ & $(0.049)$ & $(0.046)$ & $(0.076)$ & $(0.075)$ \\
\hline$R^{2}$ & 0.001 & 0.000 & 0.003 & 0.002 & 0.047 & 0.023 & 0.000 & 0.002 & 0.002 & 0.002 \\
\hline \multicolumn{11}{|c|}{ H0: fraction affected[FORMAL] $=$ fraction affected $[$ INFORM], $p$ value $=0.736$} \\
\hline \multicolumn{11}{|c|}{ Panel E: regressions with weights, $N=85$} \\
\hline \multirow{2}{*}{$\begin{array}{l}\text { Fraction } \\
\text { affected }\end{array}$} & -0.021 & $-0.082^{*}$ & $0.063^{*}$ & 0.010 & $-0.153^{*}$ & 0.095 & -0.073 & 0.023 & 0.045 & -0.025 \\
\hline & $(0.044)$ & $(0.047)$ & $(0.036)$ & (0.033) & $(0.080)$ & $(0.092)$ & $(0.048)$ & $(0.033)$ & $(0.072)$ & $(0.061)$ \\
\hline$R^{2}$ & 0.003 & 0.030 & 0.040 & 0.001 & 0.068 & 0.014 & 0.026 & 0.003 & 0.006 & 0.001 \\
\hline \multicolumn{11}{|c|}{ H0: fraction affected $[$ FORMAL $]=$ fraction affected $[$ INFORM], $p$ value $=0.039$} \\
\hline
\end{tabular}

Note: Standard errors are in parentheses

${ }^{*} p<0.10$; ${ }^{* *} p<0.05 ;{ }^{* * *} p<0.01$

informal one owing to the minimum wage hike. Furthermore, the coefficient on female employment rate is negative and large in absolute value, although it fails to achieve statistical significance at conventional levels. Note that the lack of significance may stem from the paucity of the degrees of freedom, given that the regressions are estimated on 17 observations only. Overall, these results are consistent with adverse effects of the minimum wage hike on employment, including the substitution of informal for formal employment.

When we estimate the regressions on the sub-sample that excludes the regions in the North (panel D), we find two statistically significant coefficients. The hike in the minimum wage appears to have reduced youth employment and increased youth unemployment. The test for the difference in the key coefficient in columns 2 and 3 does not reject the null $(p$ value $=0.74)$. 
Table 4 Regression results for the specification with lagged dependent variable as control variables

\begin{tabular}{|c|c|c|c|c|c|c|c|c|c|c|}
\hline & (1) & (2) & (3) & (4) & (5) & (6) & (7) & (8) & (9) & (10) \\
\hline & EMPLOY & FORMAL & INFORM & UNEMPL & YOUT_E & YOUT_U & FEM_E & FEM_U & LOW_E & LOW_U \\
\hline \multicolumn{11}{|c|}{ Panel A: all regions, $N=85$} \\
\hline \multirow[t]{2}{*}{ Fraction affected } & -0.005 & -0.035 & 0.041 & -0.003 & -0.051 & 0.064 & -0.057 & -0.001 & -0.003 & -0.006 \\
\hline & $(0.044)$ & $(0.058)$ & $(0.039)$ & $(0.040)$ & $(0.088)$ & $(0.094)$ & $(0.046)$ & $(0.045)$ & $(0.073)$ & $(0.067)$ \\
\hline$R^{2}$ & 0.124 & 0.227 & 0.089 & 0.074 & 0.224 & 0.197 & 0.101 & 0.012 & 0.168 & 0.032 \\
\hline \multicolumn{11}{|c|}{$\begin{array}{l}\text { Ho: fraction affected }[\text { FORMAL }]=\text { fraction affected }[\text { INFORM], } \\
p \text { value }=0.379\end{array}$} \\
\hline \multicolumn{11}{|c|}{ Panel B: regions with federal minimum wage, $N=68$} \\
\hline \multirow[t]{2}{*}{ Fraction affected } & 0.054 & 0.057 & 0.022 & -0.049 & 0.024 & -0.084 & 0.006 & -0.053 & -0.024 & -0.053 \\
\hline & $(0.075)$ & $(0.097)$ & $(0.069)$ & $(0.090)$ & $(0.131)$ & $(0.160)$ & $(0.097)$ & $(0.095)$ & $(0.124)$ & $(0.147)$ \\
\hline$R^{2}$ & 0.165 & 0.249 & 0.076 & 0.074 & 0.226 & 0.203 & 0.117 & 0.014 & 0.165 & 0.028 \\
\hline \multicolumn{11}{|c|}{$\begin{array}{l}\text { H0: fraction affected [FORMAL }]=\text { fraction affected }[\text { INFORM], } \\
p \text { value }=0.811\end{array}$} \\
\hline \multicolumn{11}{|c|}{ Panel C: regions with own minimum wage, $N=17$} \\
\hline \multirow[t]{2}{*}{ Fraction affected } & $-0.108^{* *}$ & $-0.195^{*}$ & 0.076 & -0.003 & -0.226 & 0.233 & $-0.130^{* *}$ & -0.035 & -0.157 & 0.004 \\
\hline & $(0.048)$ & $(0.099)$ & $(0.065)$ & $(0.028)$ & $(0.149)$ & $(0.140)$ & $(0.045)$ & $(0.044)$ & $(0.112)$ & $(0.071)$ \\
\hline$R^{2}$ & 0.136 & 0.278 & 0.162 & 0.185 & 0.348 & 0.261 & 0.162 & 0.215 & 0.387 & 0.173 \\
\hline \multicolumn{11}{|c|}{$\begin{array}{l}\text { H0: fraction affected[FORMAL }]=\text { fraction affected }[\text { INFORM }] \\
p \text { value }=0.040\end{array}$} \\
\hline \multicolumn{11}{|c|}{ Panel D: Northern regions are dropped, $N=60$} \\
\hline \multirow[t]{2}{*}{ Fraction affected } & 0.014 & -0.017 & 0.016 & 0.036 & -0.131 & $0.186^{* *}$ & -0.001 & 0.029 & 0.003 & 0.083 \\
\hline & $(0.048)$ & $(0.059)$ & $(0.041)$ & $(0.037)$ & $(0.085)$ & $(0.090)$ & $(0.046)$ & $(0.045)$ & $(0.068)$ & $(0.062)$ \\
\hline$R^{2}$ & 0.037 & 0.305 & 0.145 & 0.018 & 0.171 & 0.144 & 0.025 & 0.002 & 0.102 & 0.019 \\
\hline
\end{tabular}


Table 4 Regression results for the specification with lagged dependent variable as control variables (Continued)

\begin{tabular}{|c|c|c|c|c|c|c|c|c|c|c|}
\hline \multicolumn{11}{|c|}{ Panel E: regressions with weights, $N=85$} \\
\hline \multirow[t]{2}{*}{ Fraction affected } & -0.021 & -0.077 & $0.062^{*}$ & 0.012 & $-0.143^{* *}$ & 0.082 & $-0.066^{*}$ & 0.020 & -0.003 & -0.006 \\
\hline & $(0.038)$ & $(0.054)$ & $(0.035)$ & $(0.030)$ & $(0.069)$ & $(0.082)$ & $(0.039)$ & $(0.031)$ & $(0.056)$ & $(0.052)$ \\
\hline$R^{2}$ & 0.164 & 0.075 & 0.042 & 0.125 & 0.249 & 0.236 & 0.221 & 0.061 & 0.248 & 0.108 \\
\hline \multicolumn{11}{|c|}{ H0: fraction affected[FORMAL] $=$ fraction affected [INFORM], $p$ value $=0.071$} \\
\hline
\end{tabular}

H0: fraction affected[FORMAL $]=$ fraction affected $[$ INFORM], $p$ value $=0.071$

${ }^{*} p<0.10$; ${ }^{* *} p<0.05 ;{ }^{* * *} p<0.01$ 
Table 5 Regression results for the specification with lagged dependent variable as well as change in industrial production and share of rural population as controls

\begin{tabular}{|c|c|c|c|c|c|c|c|c|c|c|}
\hline & $(1)$ & $(2)$ & (3) & (4) & (5) & $(6)$ & (7) & (8) & (9) & (10) \\
\hline & EMPLOY & FORMAL & INFORM & UNEMPL & YOUT_E & YOUT_U & FEM_E & FEM_U & LOW_E & LOW_! \\
\hline \multicolumn{11}{|c|}{ Panel A: all regions, $N=85$} \\
\hline \multirow{2}{*}{$\begin{array}{l}\text { Fraction } \\
\text { affected }\end{array}$} & 0.010 & -0.011 & 0.032 & 0.014 & -0.035 & 0.064 & -0.050 & 0.026 & 0.031 & 0.005 \\
\hline & $(0.049)$ & $(0.062)$ & $(0.040)$ & $(0.048)$ & $(0.098)$ & $(0.105)$ & $(0.048)$ & $(0.053)$ & $(0.079)$ & $(0.074)$ \\
\hline$R^{2}$ & 0.177 & 0.280 & 0.115 & 0.141 & 0.228 & 0.215 & 0.148 & 0.094 & 0.186 & 0.076 \\
\hline
\end{tabular}

HO: fraction affected[FORMAL] $=$ fraction affected[INFORM], $p$ value $=0.632$

Panel B: regions with federal minimum wage, $N=68$

$\begin{array}{lllllllllll}\begin{array}{l}\text { Fraction } \\ \text { affected }\end{array} & 0.059 & 0.070 & 0.026 & 0.015 & 0.073 & -0.065 & -0.031 & 0.042 & 0.018 & 0.014 \\ & (0.085) & (0.129) & (0.085) & (0.109) & (0.178) & (0.194) & (0.090) & (0.124) & (0.165) & (0.165) \\ R^{2} & 0.239 & 0.312 & 0.109 & 0.152 & 0.232 & 0.214 & 0.176 & 0.098 & 0.195 & 0.120\end{array}$

H0: fraction affected[FORMAL $]=$ fraction affected[INFORM], $p$ value $=0.817$

Panel C: regions with own minimum wage, $N=17$

\begin{tabular}{|c|c|c|c|c|c|c|c|c|c|c|}
\hline \multirow{2}{*}{$\begin{array}{l}\text { Fraction } \\
\text { affected }\end{array}$} & -0.095 & -0.149 & 0.054 & -0.005 & -0.226 & 0.175 & -0.100 & -0.047 & -0.139 & 0.016 \\
\hline & $(0.057)$ & (0.092) & $(0.076)$ & (0.035) & $(0.173)$ & $(0.106)$ & $(0.056)$ & $(0.050)$ & $(0.102)$ & $(0.072)$ \\
\hline & 0.164 & 0.362 & 0.215 & 0.210 & 0.350 & 0.316 & 0.306 & 0.254 & 0.445 & .475 \\
\hline
\end{tabular}

HO: fraction affected[FORMAL] $=$ fraction affected[INFORM], $p$ value $=0.110$

Panel D: Northern regions are dropped, $N=60$

$\begin{array}{lllllllllll}\begin{array}{l}\text { Fraction } \\ \text { affected }\end{array} & 0.006 & -0.018 & 0.022 & 0.072 & -0.132 & 0.212^{*} & -0.005 & 0.072 & 0.010 & 0.116 \\ & (0.065) & (0.075) & (0.048) & (0.051) & (0.083) & (0.121) & (0.072) & (0.054) & (0.074) & (0.079) \\ R^{2} & 0.089 & 0.328 & 0.155 & 0.135 & 0.203 & 0.166 & 0.094 & 0.120 & 0.105 & 0.107\end{array}$

HO: fraction affected [FORMAL] $=$ fraction affected [INFORM], $p$ value $=0.716$

Panel E: regressions with weights, $N=85$

\begin{tabular}{llllllllllll}
$\begin{array}{l}\text { Fraction } \\
\text { affected }\end{array}$ & -0.022 & -0.084 & $0.061^{*}$ & $0.051^{*}$ & $-0.140^{* *}$ & $0.165^{* *}$ & -0.062 & $0.060^{* *}$ & -0.030 & 0.063 \\
& $(0.039)$ & $(0.054)$ & $(0.035)$ & $(0.027)$ & $(0.062)$ & $(0.072)$ & $(0.042)$ & $(0.027)$ & $(0.063)$ & $(0.046)$ \\
$R^{2}$ & 0.169 & 0.077 & 0.047 & 0.207 & 0.320 & 0.293 & 0.223 & 0.145 & 0.289 & 0.172 \\
\multicolumn{7}{l}{ HO: fraction affected[FORMAL] = fraction affected[INFORM], $p$ value $=0.055$}
\end{tabular}

Note: The coefficients on the control variables are not shown. Standard errors are in parentheses ${ }^{*} p<0.10$; ${ }^{* *} p<0.05 ;{ }^{* * *} p<0.01$

Finally, panel E shows the results for the regression with weights. There are three statistically significant coefficients, in the regressions with formal employment, informal employment, and youth employment. The signs of these coefficients are consistent with adverse effects of the minimum wage on employment. There is also a statistically significant difference in the coefficients on the fraction affected variable in the regressions with formal and informal employment $(p$ value $=0.04)$.

Next, we switch to the results shown in Table 4. Similar to Table 3, we have no statistically significant results in panel A of Table 4 . The same holds for the results in panel B. While some coefficients are large, they fail to achieve statistical significance. The test for the difference in the key coefficient in columns 2 and 3 does not reject the null in both panels. 
Panel C shows several statistically significant coefficients. The minimum wage reduces the general employment rate, formal employment rate, and female employment rate. The coefficients on both youth employment rate and employment rate among the low educated are negative and large in absolute value but statistically insignificant. The coefficient on youth unemployment rate is positive and large but fails to achieve statistical significance. Importantly, there is a statistically significant difference in the main coefficient of interest in the models with formal and informal employment $(p$ value $=0.04)$.

Panel D shows the results from estimating the model on the sub-sample that excludes the regions in the North. There are only two coefficients that are economically large, namely in the regressions with the youth unemployment and youth employment rates. However, the latter is statistically insignificant. The null hypothesis on the equality of the coefficients in the models with formal and informal employment is not rejected $(p$ value $=0.71)$.

In panel E, there are three statistically significant coefficients indicating a positive effect of the minimum wage hike on informal employment and a negative effect on the youth employment rate and female employment rate. The key coefficient in the model with formal employment as the dependent variable is negative and large, although it fails to achieve statistical significance. The formal test rejects the null hypothesis on the equality of the coefficients on the fraction affected variable in the regressions with formal and informal employment at the $10 \%$ level ( $p$ value 0.07 ).

Table 5 shows the results of estimating the previous model (with a lagged dependent variable) augmented with additional control variables, the change in industrial production during the four quarters preceding the minimum wage reform, and the share of rural population. The results are similar to those for the parsimonious model. A few coefficients lose statistical significance while remaining economically large, especially in panel C (the sub-sample of regions with own minimum wages). Apparently, the model with two extra parameters cannot be estimated precisely based on 17 observations. The test does not reject the null that the key coefficients in columns 2 and 3 of panel $\mathrm{C}$ are the same $(p$ value $=0.11)$. By contrast, panel $\mathrm{E}$ contains statistically significant coefficients on five variables, including the informal employment and the youth employment and unemployment rates as well as the female unemployment rate. Moreover, the test for the equality of the coefficients in columns 2 and 3 rejects the null at the $10 \%$ level ( $p$ value $=0.06$ )

We conducted a number of additional checks (not reported in this article). First, we ran a placebo regression in which we replaced the data from November 2007 and November 2006 with data from November 2006 and November 2005, respectively. ${ }^{14}$ The fraction affected variable was taken from April 2007. As could be expected, this placebo test returned statistically insignificant coefficients (aside from a couple of wrongly signed ones). In addition, we re-ran the regressions using the difference in logs of the dependent variables, as in Wessels (2007). The results proved qualitatively similar to those discussed above. Next, we dropped the data from the Republic of Dagestan, a clear outlier in the Northeastern corner in Figs. 1 and 2, whereby the results remained qualitatively the same as reported in the main analysis. We also checked whether the results could be affected by the limitations of the wage data used in the study. In particular, we included two additional control variables in the model, 
capturing (a) the share of workers employed in small businesses and (b) the share of part-time workers in each region in 2006, both independently and jointly. The main results remained unchanged. Interestingly, adding the share of part-time workers to the list of regressors amplified the negative effect of the minimum wage on female employment. This is consistent with part-time employment being particularly common among women.

Our summary and interpretation of these findings is the following. Firstly, there is some evidence suggesting adverse employment effects of the 2007 hike in the minimum wage in Russia. In particular, the hike reduced the employment rate among young workers and promoted informalization of employment. Secondly, the result is particularly strong for the sub-sample of regions that introduced their own minimum wages. We believe that this pattern stems from the larger magnitude of the minimum wage hikes in these regions compared to those that simply followed the federal minimum. Another possibility is that the regional increases in the minimum wage were less strongly anticipated than the federal one, whereby employers could not adjust to them in advance. Indeed, the federal hikes were regular and were usually introduced after prolonged discussions among employers, trade unions, and government. By contrast, regional minimum wages only became possible after April 20, 2007, following the changes in the federal law N 54-FZ. To be effective by the start of the fourth quarter of 2007, the regional minima had to be introduced within a few months, thus likely being unexpected among employers.

We admit that the results obtained in this study may be regarded as not very strong and robust, especially against the background of a very large increase in the minimum wage. There are several potential explanations for the relative weakness of the results. First, with a cross section of 85 observations, it is virtually impossible to properly account for the heterogeneity in labor market outcomes and their dynamics across the regions. Consequently, the standard errors become too large and the coefficients on the minimum wage variables fail to achieve statistical significance. Indeed, when we attempt to reduce this heterogeneity (e.g., by excluding the Northern regions from the sample), the results become stronger. Second, the less-than-perfect quality of the data at hand may play a role. In particular, in constructing the fraction affected variable, we have to rely on wage data from the April survey of employers, which is biased towards larger and registered firms and does not exclude wages of part-time workers. Moreover, wages in this survey are reported in rather wide brackets, which forces us to resort to interpolation. If there is a sizable measurement error in the constructed variable-which is not unlikely-the regression coefficients will suffer from attenuation bias. In this case, our results should be viewed as a lower bound of the actual effect of the minimum wage on employment. Finally, the results can be at least partly explained by imperfect enforcement of the minimum wage. Indeed, poor enforcement implies that the minimum wage may have little or no impact on labor market outcomes. And there is substantial evidence that enforcement/compliance is not perfect in developing and transition countries. ${ }^{15}$

Nevertheless, our analysis retrieves many statistically significant coefficients that are consistent with adverse effects of minimum wage hikes on employment. Importantly, none of the statistically significant coefficients suggests the opposite. Overall, there is sufficient evidence to claim that large hikes in the minimum wage adversely affect 
employment-at least among certain groups of workers-as well as promote informalization of the labor market in Russia.

\section{Conclusions}

In this paper, we extend the international literature on the minimum wage using new data from Russia. Similar to many other studies focusing on transition and posttransition countries (e.g., Muravyev 2008; Gorodnichenko et al. 2009; Eicher and Schreiber 2010), we take advantage of a unique institutional setting with frequent and abrupt regulatory changes to address an important question of general interest for labor economists. Specifically, we look at the employment consequences of the sharp increase of the minimum wage from 1100 to 2300 Rubles in September 2007.

We find some evidence of adverse effects of the minimum wage on the labor market. In particular, the hike in the minimum wage upon which we focus is associated with increased youth unemployment and informality. This finding is consistent with many previous studies for both developed and developing economies (Neumark and Wascher 2008; Nataraj et al. 2014). Importantly, it is in line with the results in Muravyev and Oshchepkov (2013), which are obtained using the region panel data approach with Russian data.

Overall, our analysis supports the viewpoint that the minimum wage may be a problematic policy instrument-including in terms of tackling poverty and inequality-given that it increases unemployment among the youth and forces workers to take informal jobs, which are typically associated with lower job security, lower earnings, and a lack of social security protection.

\section{Endnotes}

${ }^{1}$ This hike is almost unprecedented among not only developed but also developing countries. We are aware of only two increases in the minimum wage similar in magnitude to the 2007 hike in Russia: one took place in Hungary in 2001 (Kertesi and Kollo 2003) and the other one occurred in Indonesia in the 1990s (Rama 2001). However, in both cases, the doubling of the minimum wage did not happen immediately. In the former case, it occurred in two steps within 1 year, while in the latter case, it took 4 years.

${ }^{2}$ There are only a handful of studies of the minimum wage policies in Russia. The list includes Kobzar (2009), Lukiyanova (2011), Muravyev and Oshchepkov (2013), Lukiyanova and Vishnevskaya (2015), and Kapelyuk (2015). However, none of these focus on the employment effects of the 2007 hike in the minimum wage.

${ }^{3}$ This can be seen as an integral part of the process of building previously missing labor market institutions during the transition from plan to market, see, e.g., Muravyev (2014).

${ }^{4}$ In the state-controlled economy of the USSR, workers living in the North and Far East were entitled by law to higher wages, introduced via the Northern multiplier, which varied from 1.15 to 2 depending on the severity of living conditions in the respective territories. The government thus tried to emulate compensating wage differentials that would have emerged in a market environment. While the privatization process of the 1990s rendered this system no longer applicable to the wage setting in most of the economy, it remained binding for the minimum wage in both private and 
public sectors until August 2007. The Northern multiplier thus implied a substantial cross-regional variation in the nominal minimum wage in Russia.

${ }^{5}$ Computing the elasticity of employment with respect to the minimum wage requires, in addition to Eq. (1), a second equation that relates wage growth to the fraction affected (see Card 1992). We do not follow this route due to the lack of necessary data on wages.

${ }^{6}$ Russia's regions are very diverse in terms of size: while some of them have over five million inhabitants, some others have fewer than 0.25 million people.

${ }^{7}$ These are not open-access data. Rosstat only provides free access to the averages of some variables over four consecutive quarters. The detailed quarterly data were made available to us through the Center for Labor Market Studies at the HSE Moscow. The official link to the survey on the Rosstat web site: http://www.gks.ru/wps/wcm/connect/ rosstat_main/rosstat/ru/statistics/publications/catalog/doc_1140097038766 as accessed on September 15, 2015.

${ }^{8}$ Rosstat considers all workers whose job is not within a firm as being informal. An important advantage of such a general definition of informality is that it is not sensitive to mistakes and non-responses of respondents when questions about the size of the firm, its official status (registered vs. unregistered), contributions to the social security funds, etc. are asked. However, this advantage can also prove to be a deficiency. In particular, it is possible that the definition omits some other important manifestations of informal employment, especially informal employment within the formal sector. Nonetheless, the available evidence from Rosstat suggests that such employment only constitutes about $1 \%$ of all informal employment. Therefore, we believe that the measure of informal employment available to us is reasonably accurate and captures the most essential aspects of this phenomenon in Russia.

${ }^{9}$ We contrast basic and general secondary education with professional and higher education.

${ }^{10}$ Web address: www.consultant.ru, as accessed on September 15, 2015.

${ }^{11}$ For example, the survey reports the percent of workers within the following wage brackets: below 1100 Rubles, from 1100 to 1800 Rubles, from 1800 to 2600 Rubles, from 2600 to 3400 Rubles, and so on. If the minimum wage changed from 1100 to 2300 Rubles (which was the case in most regions), we add up the percent of workers within the second bracket (1100 to 1800 Rubles) and $(2300-1800) /(2600-1800)=$ 0.625 times the percent of workers in the third bracket in order to obtain a measure of the fraction affected. It is not obvious whether one should incorporate the percent of workers from the first bracket (below 1100 Rubles, the old minimum wage) into the fraction affected variable. In particular, the respective numbers can be regarded as a measure of non-compliance with the old minimum wage. If employers did not comply with the old minimum wage, they are likely to ignore the new minimum. In any case, including this bracket (corresponding to $1.2 \%$ of workers nationwide) does not change our results in any substantial way.

${ }^{12}$ Similar to the mentioned papers, we compute the Kaitz index using data on average wages from the total survey of employers, which includes small firms and is run by Rosstat on a monthly basis. In contrast to the April survey of employers, this monthly survey does not provide detailed information on the distribution of wages and thus, it is not suitable for computing the fraction affected, the key variable in our analysis. 
${ }^{13}$ Interestingly, these findings are consistent with the evidence from the USA suggesting that own minimum wages (higher than the federal level) tend to be introduced by stronger regions and in economically favorable periods (Neumark et al. 2014; Baskaya and Rubinstein 2012).

${ }^{14}$ Note that there was a hike of the minimum wage on May 1, 2006, from 800 to 1100 Rubles (or 38 \%). The timing of the minimum wage changes in the mid-2000 was such that it is impossible to find four quarters without a minimum wage hike.

${ }^{15}$ However, several studies suggest a limited role of this factor in Russia. Kapelyuk (2015) analyzes the non-compliance of employers with minimum wage laws by checking the share of full-time workers with wages lower than the minimum wage in the RLMS, the best panel survey of Russian households. He finds that "non-compliance was modest, indicating that there was strong enforcement of the minimum wage agreements" (p. 403). Gimpelson et al. (2010), who study the enforcement of employment protection legislation in Russia, note that non-compliance with labor regulations is higher in the Far East and the North of the country. However, these are high-wage regions where the minimum wage bite is modest or even close zero.

\section{Competing interests}

The IZA Journal of Labor \& Development is committed to the IZA Guiding Principles of Research Integrity. The authors declare that they have observed these principles.

\section{Acknowledgements}

We are grateful to Stephen Bazen, Ravi Kanbur, an anonymous reviewer, and participants of the conference "Reforming Minimum Wage and Labor Regulation Policy in Developing and Transition Economies" held at Beijing Normal University in October 2014 for the useful comments and suggestions. The usual caveat applies. Aleksey Oshchepkov acknowledges support from the Basic Research Program of the National Research University Higher School of Economics.

Responsible editor: Haroon Bhorat, Ravi Kanbur and Li Shi.

\section{Author details}

${ }^{1}$ Saint Petersburg Branch, National Research University Higher School of Economics, Kantemirovskaya street 3 bld. 1 , Saint Petersburg 194100, Russia. ${ }^{2}$ IZA, Bonn, Germany. ${ }^{3}$ National Research University Higher School of Economics, 20, Myasnitskaya st., Moscow 101000, Russia.

Received: 16 March 2015 Accepted: 12 January 2016

Published online: 29 March 2016

\section{References}

Allegretto S, Dube A, Reich M, Zipperer B (2013) Credible research designs for minimum wage studies. Working paper, Institute for Research on Labor and Employment, UC, Berkeley

Baker M, Dwayne B, Stanger S (1999) The highs and lows of the minimum wage effect: a time-series cross-section study of the Canadian law. J Labor Econ 17(2):318-350

Baskaya YS, Rubinstein Y (2012) Using federal minimum wage effects to identify the impact of minimum wages on employment and earnings across U.S. states. Paper presented at the EEA-ESEM annual meeting, 27 - 31 August 2012, Málaga, Spain

Bazen S, Le Gallo J (2009) The state-federal dichotomy in the effects of minimum wages on teenage employment in the United States. Econ Lett 105(3):267-269

Bazen S, Skourias N (1997) Is there a negative effect of minimum wages on youth employment in France? Eur Econ Rev 41(3):723-732

Belman D, Wolfson P (2014) What does the minimum wage do? Kalamazoo, Ml: W.E. Upjohn Institute for Employment Research

Belser P, Rani U (2015) Berg J. In: Labour markets, institutions and inequality: building just societies in the 21 st century. Edward Elgar Publishing, Cheltenham

Boal W, Ransom M (1997) Monopsony in the labor market. J Econ Lit 35(1):86-112

Card D (1992) Using regional variation in wages to measure the effects the federal minimum wages. Ind Labor Relat Rev 46(1):22-37

Card D, Krueger A (1995) Myth and measurement: the new economics of the minimum wage. Princeton University Press, Princeton

Danziger L (2010) Endogenous monopsony and the perverse effect of the minimum wage in small firms. Labour Econ 17(1):224-229

Dolton P, Bondibene CR, Wadsworth J (2012) Employment, inequality and the UK national minimum wage over the medium-term. Oxford B Econ and Stat 74(1):78-106 
Dube A, Lester W, Reich M (2010) Minimum wage effects across state borders: estimates using contiguous counties. Rev Econ Stat 92(4):945-964

Eicher T, Schreiber T (2010) Structural policies and growth: time series evidence from a natural experiment. J Dev Econ 91(1):169-179

Gimpelson V, Kapelyushnikov R, Lukyanova A (2010) Employment protection legislation in Russia: regional enforcement and labor market outcomes. Comp Econ Studies 52(4):611-636

Gorodnichenko Y, Martinez-Vazquez J, Sabirianova Peter K (2009) Myth and reality of flat tax reform: micro estimates of tax evasion response and welfare effects in Russia. J Polit Econ 117(3):504-554

Kapelyuk S (2015) The effect of minimum wage on poverty. Econ Transit 23(2):389-423

Katz L, Krueger A (1992) The effect of the minimum wage on the fast-food industry. Ind Labor Relat Rev 46(1):6-21

Kertesi G, Kollo J (2003) Fighting "low equilibria" by doubling the minimum wage? Hungary's experiment., IZA Discussion Paper No. 970. Bonn, Germany: Institute for the Study of Labor (IZA)

Kobzar E (2009) Minimum wage in Russia: regional labor markets. Working Paper, Laboratory for Labor Market Studies. Higher School of Economics, Moscow (in Russian)

Krueger A (1995) The effect of the minimum wage when it really bites: a reexamination of the evidence from Puerto Rico. Res Labor E 14:1-22

Lukiyanova A (2011) Effects of minimum wages on the Russian wage distribution. Higher School of Economics research paper No. 09/EC/2011., Moscow, Russia: National Research University Higher School of Economics

Lukiyanova A, Vishnevskaya N (2015) The decentralization of minimum wage setting in Russia. Higher School of Economics research paper No. 90/EC/2015., Moscow, Russia: National Research University Higher School of Economics

Muravyev A (2008) Human capital externalities: evidence from the transition economy of Russia. Econ Transit 16(3):415-443

Muravyev A (2014) The evolution of the regulation of labour in the USSR, the CIS and the Baltic states, 1985-2009. Europe-Asia Stud 66(8):1270-1294

Muravyev A, Oshchepkov A (2013) Minimum wages, unemployment and informality: evidence from panel data on Russian regions. IZA Discussion Paper No. 7878., Bonn, Germany: Institute for the Study of Labor (IZA)

Nataraj S, Perez-Arce F, Kumar K, Srinivasan S (2014) The impact of labor market regulation on employment in lowincome countries: a meta-analysis. J Econ Surv 28(3):551-572

Neumark D, Wascher W (1992) Employment effects of minimum and subminimum wages: panel data on state minimum wage laws. Ind Labor Relat Rev 46(1):55-81

Neumark D, Wascher W (2008) Minimum wages. The MIT Press, Cambridge

Neumark D, Salas I, Wascher W (2014) Revisiting the minimum wage-employment debate: throwing out the baby with the bathwater? Ind Labor Relat Rev 67(3):608-648

Rama M (2001) The consequences of doubling the minimum wage: the case of Indonesia. Ind Labor Relat Rev 54(4): 864-881

Sen A, Rybczynski K, Van De Waal C (2011) Teen employment, poverty, and the minimum wage: evidence from Canada. Labour Econ 18(1):36-47

Stewart M (2002) Estimating the impact of the minimum wage using geographical wage variation. Oxford B Econ Stat 64(S):583-605

Stigler G (1946) The economics of minimum wage legislation. Am Econ Rev 36(3):358-365

Wessels W (2007) A reexamination of Card and Krueger's state-level study of the minimum wage. J Labor Res 28(1):135-146

Submit your manuscript to a SpringerOpen ${ }^{\odot}$ journal and benefit from:

- Convenient online submission

- Rigorous peer review

- Immediate publication on acceptance

Open access: articles freely available online

- High visibility within the field

- Retaining the copyright to your article

Submit your next manuscript at $>$ springeropen.com 